\title{
Analysis of Thermally-stable Electron Transport Factors from the Hyperthermophilic Archaebacterium Pyrodictium brockii
}

\section{Project Description/Introduction}

The mechanisms by which hyperthermophilic archaebacteria grow and carry out metabolic functions at elevated temperatures have yet to be determined. The objective of this work is to develop an understanding of the metabolic characteristics of, and the electron transport enzymes involved in, hydrogen/sulfur transformation by hyperthermophilic archaebacteria. Efforts will focus on the autotrophic $\mathrm{H}_{2}$-oxidizing bacterium, Pyrodictium brockii, which has a reported optimum growth temperature of $105^{\circ} \mathrm{C}$ in pure culture. Biochemical and genetic characterization of enzymes involved in hydrogen oxidizing electron transport pathway will be pursued. These include investigating the role of the membrane lipids in protecting the hydrogenase enzyme from thermal inactivation, characterization of a quinone and a c-type cytochrome, and analysis of the topology in the membrane in the net energy generating components. The purified $\underline{\text { p brockii }}$ hydrogenase will be reconstituted into different (archaebacterial) lipid environments and thermal stability of electron transport components with mesophilic counterparts is a major goal. The quinone will be biochemically analyzed, and the gene encoding the c-type cytochrome will be cloned and sequenced to obtain the predicted amino acid sequence. The long-term goal is to understand some of the factors contributing to the biochemical basis of extreme thermophily.

\section{DISCLAIMER}

This report was prepared as an account of work sponsored by an agency of the United States Government. Neither the United States Government nor any agency thereof, nor any of their employees, makes any warranty, express or implied, or assumes any legal liability or responsibility for the accuracy, completeness, or usefulness of any information, apparatus, product, or process disclosed, or represents that its use would not infringe privately owned rights. Reference herein to any specific commercial product, process, or service by trade name, trademark, manufacturer, or otherwise does not necessarily constitute or imply its endorsement, recommendation, or favoring by the United States Government or any agency thereof. The views and opinions of authors expressed herein do not necessarily state or reflect those of the United States Government or any agency thereof. 


\section{Progress Report}

Previously, we worked out conditions so that suitable yields of . brockii could be obtained for use in biochemical studies. The continuous culture set up, now running continuously in my lab permits us to harvest about $0.1 \mathrm{~g}$ of cells per $48 \mathrm{hr}$. This represents a 20-fold better yield than that which we coula obtain just 2 years ago.

\section{Progress in delineating the pathway of electrons from $\mathbf{H}_{2}$ to $S$ in $\underline{P}$. brockii}

P. brockii grows in an $\mathrm{H}_{2} / \mathrm{CO}_{2}$ atmosphere in the presence of elemental sulfur at temperatures exceeding $100^{\circ} \mathrm{C}$. Our work has focused on the metabolic properties, especially the energygenerating $\mathrm{H}_{2}$-oxidizing electron transport chain of $\underline{\mathrm{P}}$. brockii. A comparison of the components of this electron transport chain with well-characterized mesophilic counterparts should aid in our understanding of the biochemical basis for hyperthermophily.

\section{A. Hydrogenase}

The hydrogenase enzyme from Pyrodictium brockii has been purified (Pihl and Maier, J. Bact. 173: 1839-1844 (1991), manuscript enclosed). Solubilization from membranes required treatment with 3\% Triton $x-100$. Most interestingly, the purified enzyme is much less thermally stable than the membrane-bound enzyme. The purified enzyme is composed of two subunits (one each of $66 \mathrm{kDa}$ and $45 \mathrm{kDa}$ ) and the holoenzyme has a MW of $118 \pm$ $19 \mathrm{kDal}$. It contains iron and acid-labile sulfur, as well as nickel. The subunit structure, metal content and electron acceptor specificity indicates the enzyme is much more similar to the $\mathrm{H}_{2}$ uptake hydrogenases of eubacteria, rather than like the $\mathrm{H}_{2}$ metabolizing system in anaerobes or in the hyperthermophile that was co-isolated with $\underline{p}$. brockii, Pyrococcus furiosus. The large subunit of $\underline{P}$. brockii hydrogenase reacts with anti-B. japonicum large subunit antibody. The $k_{m}$ of the membrane-bound hydrogenase for $\mathrm{H}_{2}$ was approximately $19 \mu \mathrm{M}$ whereas the purified enzyme had a higher $K_{m}$ value (in most experiments more than $100 \mu \mathrm{M}$ ). It was concluded that the membrane appears to play a role in thermal stability and catalytic efficienc; (ref. 4 of Progress Report).

\section{B. Quinone}

Extraction studies as well as -econstitution experiments suggested a ubiquinone-like electron transport factor exists in P. brockii membranes (Pihl, et al. J. Bacteriol. 174: 137-141. (1992)). The UV-light sensitive component mediates electron flow from $\mathrm{H}_{2}$ to cytochrome(s). NMR and mass spectral analysis suggest this component may be similar to ubiquinone-6, but definitive molecular structural data must await further physical studies. The data from physical studies thus far has not matched the data of any of a number of menaquinones, ubiquinones, plastoguinones, or even published data on unique quinones. Nevertheless, the 
preliminary physical analysis is consistent with a 6 member isoprenoid unit and a ring structure similar to UQ; including a $\mathrm{C}-\mathrm{Ch}_{3}$ band off of the ring. Thin-layer chromatographic studies were consistent with the $\underline{P}$. brockii quinone being similar to $Q_{6}$, and the chromatographic separations allowed the purification of the quinone. As novel lipids and quinones have been found in Smetabolizing archaebacteria the structure of the quinone in $\underline{P}$. brockii may prove to be interesting. Electron transport (in quinone-depleted vesicles) from $\mathrm{H}_{2}$ to $\mathrm{S}^{\circ}$ is restored by addition of $Q_{6}, Q_{10}$ or the purified . brockii quinone, and use of the quinone analngue HQNO demonstrated the quinone is located on the $\mathrm{H}_{2}$ substrate side of the electron transport chain with respect to cytochrome. These first characterizations of the strictly anaerobic, presumably primitive $\underline{\text {. }}$ brockii electron transport chain suggest that the hydrogenase operates at a relatively high redox potential and that the $\mathrm{H}_{2}$-oxidizing chain more closely resembles those of aerobic eubacterial $\mathrm{H}_{2}$-oxidizing bacteria than those of the $\mathrm{H}_{2}$-metabolizing systems of anaerobes or the hyperthermophile pyrococcus furiosus.

\section{Cytochnome}

A c-type cytochrome, $c-553$, has been observed in $\mathrm{H}_{2}$-reduced minus $\mathrm{S}^{\circ}$ or $\mathrm{O}_{2}$ oxidized membrane samples from batch-grown $\underline{\mathrm{P}}$. brockii. Inhibitor experiments place this component between quinone and $S^{\circ}$ in the electron transport chain (Pihl, et al., J. Bacteriol. 174: 137-141 (1992)). A c-type cytochrome with alpha, beta, and gamma peaks at 553, 522, and $421 \mathrm{~nm}$ was solubilized from membranes with $0.5 \%$ Triton $x-100$. Once this component is extracted from the membrane, no other cytochrome remains membrane-bound. Heme-staining of SDS gels has confirmed the presence of a single c-type cytochrome in solubilized membranes with a subunit molecular weight of 13-14,000. Further characterization of the cytochrome and isolation of the gene encoding it is work in progress.

\section{D. $S^{\circ}$ reduction}

our initial goal was to isolate $\mathrm{H}_{2}$ oxidizing s-reducing membrane particles of $\underline{P}$. brockii in order to study the sequential electron transport components. This was accomplished (see below references 1 and 2 ). Our experiments with the membranes show that $S$ acts as the only terminal electron acceptor, and that two $\mathrm{H}_{2}$ atoms are utilized per one $\mathrm{S}$ atom reduced to $\mathrm{H}_{2} \mathrm{~S}$. The latter result is important to show that other (endogenous) electron donors are not present in the membranes, which allows definitive conclusions on the sequence of electron transport proteins from the difference absorption spectral experiments. Recently, some progress has been made in assaying the $S$ oxidoreductase of $\underline{p}$. brockii membranes. Use of phenosafranine proved to be a suitable electron donor to assay $S$-dependent $\mathrm{H}_{2} \mathrm{~S}$ production (Bingham and Maier, unpublished). Strictly anaerobic conditions must be maintained for this assay, and the activity is associated only 
with membranes, not the soluble fraction of cell extracts. This assay will be useful for analysis of the topological membrane orientation of the reductase, in order to learn about the energy generating mechanisms (sidedness with respect to proton consumption sites) across the membrane (see objective 5 below).

\section{Progress in developing the molecular genetics of $\underline{\mathbf{P}}$. brockii}

A key approach to understanding thermal stability of proteins, I feel, is to compare the intrinsic properties of a single catalytic prucess (enzyme) between mesophilic and thermophilic organisms. of the components we are studying biochemically (see above), the c-type cytochrome and the hydrogenase are two excellent candidates for this comparison. The preparation of gene banks containing $\underline{P}$. brockii genomic DNA has been accomplished. This was not a simple task (see previous Progress Report on the failures of this, submitted in June of 1991). A suitable $\underline{\text {. }}$. brockil gene bank in a phage library (EMBL3) shows promise for obtaining a hydrogenase and a cytochrome c gene.

An initial attempt to clone the hydrogenase gene was made using a Bradyrhizobium japonicum hydrogenase clone (which had

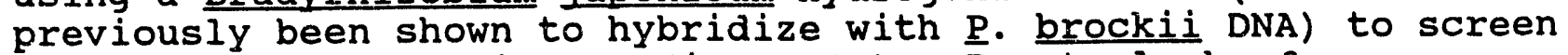
a p. brockii phage library (in EMBL3). Due to lack of significant homology, we were unable to locate a clone using this method. Current attempts are under way using two methods; Nterminal sequencing of the protein and using synthetic oligonucleotides and PCR to make a homologous probe. The first method has been slowed by lack of biomass. Two 18-mer oligonucleotides were synthesized which shared homology to two areas amongst the large subunit of several hydrogenases. These oligonucleotides were used along with $\underline{\text {. }}$. brocki $i$ DNA as a template, in a PCR reaction to make a better probe. This latter $\sim \mathrm{kb}$ probe is being used to screen the P. brcckii library.

The same method (synthetic oligonucleotides and using PCR) was used in attempts to clone the cytochrome $c$ gene. Using the consensus heme binding pocket found in all c-type cytochromes and an $\mathrm{N}$-terminal homologous region found in cytochrome $c^{\prime} s$ of sulfur- and sulfate-reducing bacterı, synthetic oligonucleotides were made. Again, these oligonucleotides were used, along with P. brockii template DNA, in a PCR reaction. This 250 bp probe has been sequenced and contains the heme-binding pocket, therefore the amplified segments appear to be very promising tools to obtain the cytochrome $c$ gene of $\underline{p}$. brockij. Screening

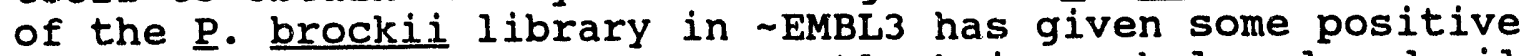
clones. These clones are currently being subcloned and will be sequenced. With the data the emphasis will be on comparison of the sequence with well-characterized cytochrome $c$ sequences from mesophilic organisms. 


\section{BRIEF SYNOPSIS OF FUTURE PLANS}

The components listed above in the electron transport chain -- hydrogenase, quinone, and cytochrome $c$, will be further characterized biochemically. For example, the specific molecular structure of the quinone is of interest, and the amino acid sequence including analysis for putative heme-binding ligands of the cytochrome $c$ will receive top priority. The electron transport components to be studied function in membranes at high temperatures, as the quinone and cyt $C$ are $\mathrm{H}_{2}$ reducible at $95^{\circ} \mathrm{C}$ (ref. \#5 of Progress Report). The role of the membrane in conferring thermal stability to hydrogenase will now be investigated in more detail. For example, the purified hydrogenase enzyme will be reconstituted into different (archaebacterial) lipid environments and thermal stability measured. For this goal, larger amounts of hydrogenase have been purified and stored at $-70^{\circ} \mathrm{C}$. By reconstituting the enzyme into lipids, the effects of different lipids on membrane protein thermal stability can be assessed. The quinone that we now know functions between hydrogenase and cytochrome $c$ will be further characterized by physical methods (NMR and mass spectral studies). An understanding of the energy-generating mechanism (scalar proton production versus direct coupling mechanism) operating at approximately $100^{\circ} \mathrm{C}$ is also desired. For this purpose, the sulfur oxidoreductase has been localized to the membrane (see above) and it will be further studied in membrane vesicles. The specific objectives of the work remain as in the original proposal (Plan of Work, page 5 of proposal). They are the following:

1) Determine the possible role of archaebacterial membrane lipids in providing thermal stability to a membrane bound enzyme, p. brockii hydrogenase.

2) Purification and characterization of a c-type cytochrome from pyrodictium brockii.

3) Isolation of the gene encoding the P. brockii c-type cytochrome. The gene will be sequenced so that we can compare the predicted amino acid sequence and the predicted structure with mesophilic cytochrome c's.

4) Determine the structure of a quinone from p. brockii membranes.

5) Determine the relative topological membrane orientation of the hydrogenase and the $S^{\circ}$ reductase in order to predict scalar proton production. If the proton producing hydrogenase and the proton-consuming sulfur oxidoreductase are situated on the same side of the membrane, other energygenerating mechanisms (direct proton pumping mechanism) must be investigated for $\mathrm{H}_{2} / \mathrm{S}$ hyperthermophily. 


\section{List of Publications 1989-1992 (DOE-supported work only)}

1. Pihl, T.D., R. N. Schicho, R.M. Kelly, al R.J. Maier. 1989. Characterization of hydrogen uptake activity in the hyperthermophile pyrodictium brockii. Proc. Natl. Acad. Sci. U.S.A. 86: 138-141.

2. Pihl, T.D., R.N. Schicho, L. Black, R.J. Maier, and R.M. Kelly. 1990. Hyarogen-sulfur autotrophy in the hyperthermophilic archaebacterium Pyrodictium brockii. Biotechnol. and Genetic Engineering Reviews, Intercept. Ltd. Vol. 8, pp. 345-378.

3. Pihl, T.D., R.N. Schicho, R.M. Kelly, and R.J. Maier. 1990. Physiological aspects of hydrogen sulfur autotrophy in pyrodictium brockii. Proceedings from the IGT International Symposium on Gas, Oil, and Coal Biotechnology, pp. 145-153.

4. Pihl, T.D. and R.J. Maier. 1991. Purification and characterization of the hydrogen-uptake hydrogenase from the hyperthermophilic archaebacterium pyrodictium brockii. J. Bacteriol. 173: 1839-1844.

5. Pihl, T.D., L.K. Black, B.A. Schulman, and R.J. Maier. 1992 . Hydrogen oxidizing electron transport components in hyperthermophıiic archaebacterium Pyrodictium brockii. J. Bacteriol. 174: 137-143.

6. Maier, R.J., L.K. Black, and T.D. Pihl and B. Schulman. 1992. Respiratory electron transport components in hyperthermophilic bacteria. In: "Biocatalysis at extreme temperatures," American Chem. Soc., Washington, D.C. (M.W.W. Adams and R.M. Kelly, eds.) 

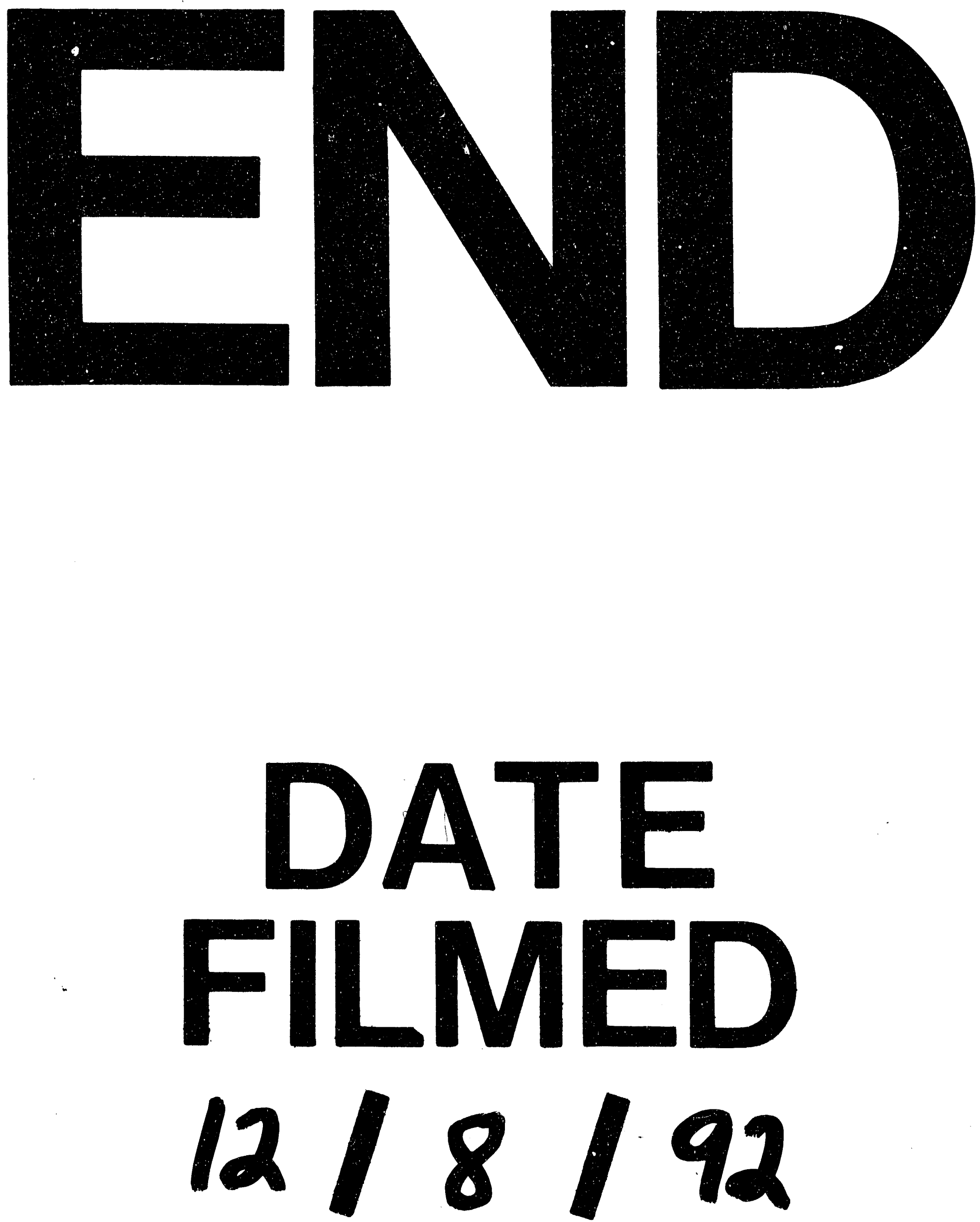
